\title{
Pulmonary venous abnormalities encountered on pre-radiofrequency ablation mapping multidetector computed tomography
}

\begin{tabular}{|c|c|}
\hline \multicolumn{2}{|l|}{$\begin{array}{l}\text { Authors: } \\
\text { Paul Cronin } \\
\text { Aine M. Kelly }\end{array}$} \\
\hline \multicolumn{2}{|c|}{$\begin{array}{l}\text { Affiliations: } \\
{ }^{1} \text { Department of Radiology, } \\
\text { Division of Cardiothoracic } \\
\text { Radiology, University of } \\
\text { Michigan Medical Center, } \\
\text { United States }\end{array}$} \\
\hline \multicolumn{2}{|c|}{$\begin{array}{l}\text { Corresponding author: } \\
\text { Paul Cronin, } \\
\text { pcronin@med.umich.edu }\end{array}$} \\
\hline \multicolumn{2}{|c|}{$\begin{array}{l}\text { Dates: } \\
\text { Received: } 21 \text { Feb. } 2017 \\
\text { Accepted: } 05 \text { Apr. } 2017 \\
\text { Published: } 03 \text { July } 2017\end{array}$} \\
\hline \multicolumn{2}{|c|}{$\begin{array}{l}\text { How to cite this article: } \\
\text { Cronin P. Kelly AM. } \\
\text { Pulmonary venous } \\
\text { abnormalities encountered } \\
\text { on pre-radiofrequency } \\
\text { ablation mapping } \\
\text { multidetector computed } \\
\text { tomography. S Afr J Rad. } \\
\text { 2017; } 21(1) \text {, a1189. https:// } \\
\text { doi.org/10.4102/sajr. } \\
\text { v21i1.1189 }\end{array}$} \\
\hline \multicolumn{2}{|c|}{$\begin{array}{l}\text { Copyright: } \\
\text { (c) 2017. The Authors. } \\
\text { Licensee: AOSIS. This wo } \\
\text { is licensed under the } \\
\text { Creative Commons } \\
\text { Attribution License. }\end{array}$} \\
\hline \multicolumn{2}{|c|}{ Read online: } \\
\hline 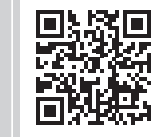 & $\begin{array}{l}\text { Scan this QR } \\
\text { code with your } \\
\text { smart phone or } \\
\text { mobile device } \\
\text { to read online. }\end{array}$ \\
\hline
\end{tabular}

Multidetector computed tomography (MDCT) elegantly renders pulmonary venous anatomy. With increasing numbers of radiofrequency ablation procedures being performed, there is now a greater emphasis on pre-procedure imaging to delineate this anatomy. Pulmonary venous mapping studies can be performed with or without ECG-gating. However, ECGgating improves both the quality of 3D images and the accuracy of pulmonary vein (PV) ostial diameter measurements. Including the superior thorax, and not just the left atrium and central PVs, allows visualization of aberrant pulmonary venous drainage to the brachiocephalic veins or superior vena cava. Normally, there are two superior PVs, one right and one left, and two inferior PVs, one right and one left. The right superior vein usually drains the right upper and middle lobe. The left superior vein drains the left upper lobe including the lingula. The inferior veins drain their respective lower lobe. PV anatomy is more variable than pulmonary arterial anatomy, and developmental anomalies are common. This article describes, illustrates and reviews the common anomalies of the PVs in our experience performing over 1000-preradiofrequency ablation cardiac MDCT studies. The commonest anomalies are supernumerary or accessory veins (on the right) and a (left) common trunk. More rarely, partial anomalous pulmonary venous return and Cor triatriatum are seen, and rarest of all is total anomalous pulmonary venous return, PV varix and single or multiple vein stenosis or atresia.

\section{Introduction}

For over two decades, computed tomography $(\mathrm{CT})$ has provided users with precise images of the pulmonary vascular anatomy. More recently, there has been increased interest in the clinical and radiology literature regarding normal or anomalous pulmonary vascular anatomy. With the wide variety of percutaneous endoluminal diagnostic and therapeutic procedures now available, and innovative new procedures such as pulmonary vein (PV) and left atrial ablation performed more commonly, the need to know the normal pulmonary vascular anatomy and common anomalies has increased. There is now a greater emphasis on preprocedure imaging to delineate anatomy using thin collimation multidetector computed tomography (MDCT), which elegantly depicts the precise anatomy. Using MDCT scans obtained for PV mapping prior to radiofrequency ablation, the common anomalies of the PVs are reviewed.

Atrial fibrillation (AF) is both the most common cardiac arrhythmia and sustained supraventricular arrhythmia. Electrical disconnection with catheter ablation within the PV or in the posterior left atrium (LA) around the PV ostium is a recognised therapeutic option. Pre-ablation imaging is crucial for the effectiveness of the ablation procedure. Whether performing vein ablation or employing newer techniques using circumferential extraostial ablation, it is also important to know the ostial orientation and diameter and presence or absence of venous anomalies. To maximize success rates, all veins require ablation. However, anomalous PV ostia are significantly smaller when accessory or larger when a common trunk than the superior or inferior PV ostia. Therefore, these vein ablations may require smaller or larger catheters. Pre-ablation imaging can minimise catheter-related complications and improve procedural success rates by documenting PV ostial anatomy, ostial sizes and variants.

The purpose of this article is to describe the common anomalies of the PVs illustrated with our experience in performing over 1000 pre-radiofrequency ablation cardiac MDCT mapping studies. A selection of CT images to illustrate the common anomalies of the PVs is presented. 


\section{Pulmonary vein imaging}

Left atrium and PV mapping using helical CT scanners has been performed since the invention of the MDCT scanner using 4-, 8-, 16-, 64- and >64-detector scanners. Currently, at our institution, patients are scanned on a 64-detector scanner. Some institutions use ECG-gating while others do not. ECGgating can be performed in patients in sinus rhythm. In general, one-third to one-half of patients undergoing these studies cannot undergo ECG-gated examinations because of arrhythmias. As there is both phasic change in PV ostial diameters and phasic change in ostial positions during the cardiac cycle, ECG-gating allows assessment of the PVs at a single phase of the R-R interval, such as $75 \% \mathrm{R}-\mathrm{R}$, that is, end diastole when there is least cardiac motion and maximal venous distention. ${ }^{1}$ Another advantage of ECG-gating is it improves both the quality of $3 \mathrm{D}$ images and the ability to detect thrombus within the LA and/or left atrial appendage. A disadvantage of ECG-gating is increased radiation dose. Test bolus timing with a region of interest placed in the LA can be employed to determine the peak enhancement within the LA. Non-ionic intravenous contrast material in total administered with a power-injector at a rate of approximately $4 \mathrm{~mL} / \mathrm{sec}-5 \mathrm{~mL} / \mathrm{sec}$ through an antecubital vein is generally used. The collimation used is approximately $1 \mathrm{~mm}$, with a sub-millimetre reconstruction interval. The heart or the entire thorax may be scanned during a single breath-hold. Including the superior thorax, and not just the LA and central PVs, allows visualization of aberrant pulmonary venous drainage to the brachiocephalic veins or superior vena cava (SVC). ${ }^{1}$ For an average-sized adult male patient, the effective radiation dose for a scan performed without ECG-gating is approximately $10 \mathrm{mSv} .^{1}$ Studies performed with ECG-gating have a radiation dose of approximately $15 \mathrm{mSv}$ for prospective gating and $20 \mathrm{mSv}$ for retrospective gating. The acquired images can be reviewed as axial data, multiplanar reformatted images or using advanced processing such as volume rendering or endocardiac views.

\section{Pulmonary vein embryology}

Veins develop in the mesoderm, which first becomes converted into blood islands and later unite to form vessels. The venous system is made up of two main groups of veins, the cardinal system, which drains the body wall, and the vitelline system. The vitelline veins go on to form the PVs, the inferior vena cava (IVC) and the portal vein. The PVs start as a network of capillaries around the lungs. By the fourth week of embryogenesis, the primitive common PV appears as a solid outgrowth from the sinoatrial region of the heart. ${ }^{2}$ This outgrowth projects caudally and eventually connects with the foregut venous plexus, above where the lung buds will form. At this stage, the foregut has not split into the ventral respiratory tube and dorsal alimentary tube. When this occurs, they acquire separate communications to the heart, ${ }^{2}$ the alimentary tube via the cardinal veins, which will become the SVC and azygos system, and the respiratory tube via PVs, which drain through the common PV into the LA. The common PV divides into a right and left branch, which then further bifurcates. Later the growing LA absorbs the common PV and first order branches resulting in four PVs, the right and left superior and inferior PV. $2,3,4$

\section{Pulmonary vein normal anatomy}

There are four PVs, two superior PVs and two inferior PVs, one right and one left respectively. The right superior vein usually drains the right upper and middle lobe. The left superior vein drains the left upper lobe including the lingula. The inferior veins drain their respective lower lobe (Figure 1). ${ }^{1}$

The PVs are separate from the bronchoarterial bundles, and take a different course/angle as well, especially the superior veins. The right superior pulmonary vein (RSPV) passes inferomedially, posterior to the SVC and initially anterior to the right pulmonary artery before passing below it to enter the most superolateral aspect of the LA. The left superior pulmonary vein (LSPV) also passes inferomedially, anterior
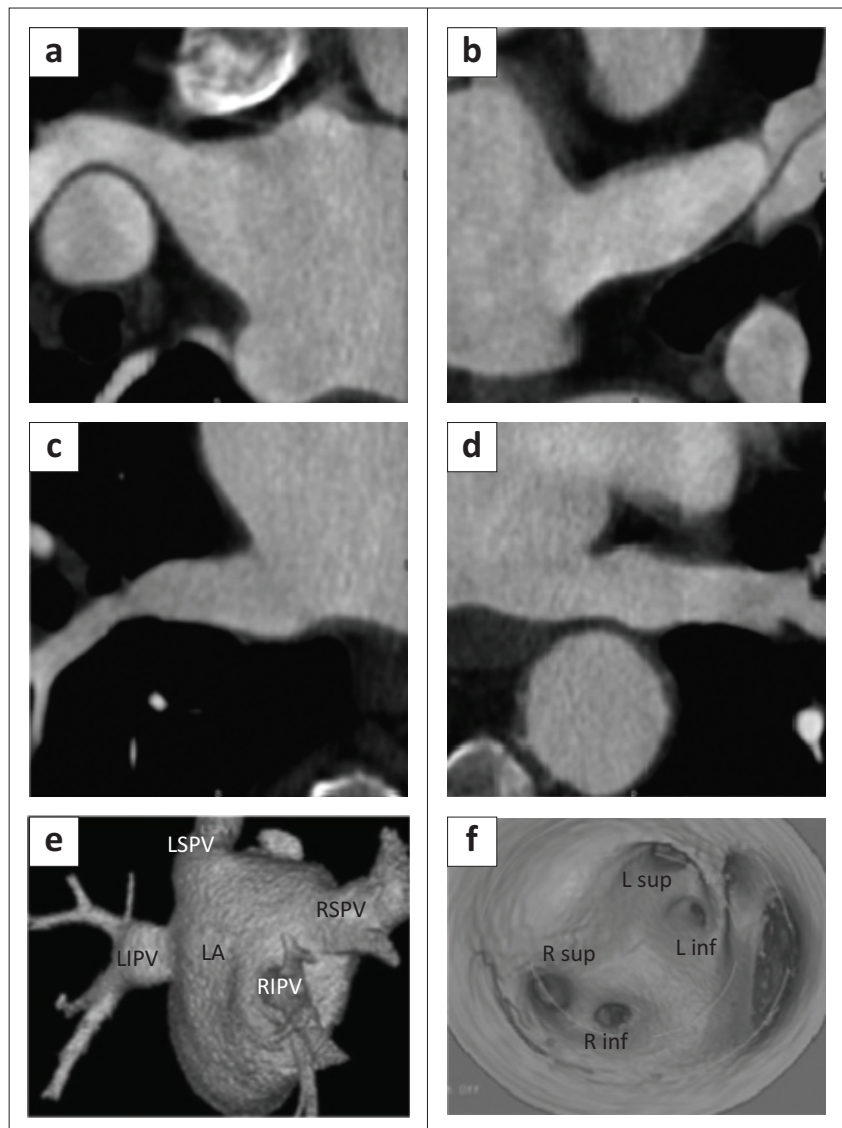

RSPV, right superior pulmonary vein; RIPV, right inferior pulmonary vein; LSPV, left superior pulmonary vein; LIPV, left inferior pulmonary vein; LA, left atrium; $R$ sup, right superio pulmonary vein; $R$ inf, right inferior pulmonary vein; $L$ sup, left superior pulmonary vein; $L$ inf, left inferior pulmonary vein.

FIGURE 1: Normal pulmonary vein anatomy displayed on long axis reformatted computed tomography images in a 73 year-old man prior to radiofrequency ablation therapy for atrial fibrillation: (a) Right superior pulmonary vein; (b) Left superior pulmonary vein; (c) Right inferior pulmonary vein; (d) Left inferior pulmonary vein; (e) Three-dimensional models of normal left atrium and pulmonary vein anatomy showing the right superior pulmonary vein (RSPV), right inferior pulmonary vein (RIPV), left superior pulmonary vein (LSPV), left inferior pulmonary vein (LIPV) and left atrium (LA); (f) Endocardial views of the left atrium and pulmonary veins showing normal anatomy with the right superior pulmonary vein ( $R$ sup), right inferior pulmonary vein ( $R$ inf), left superior pulmonary vein ( $L$ sup) and left inferior pulmonary vein ( $L$ inf), with annotation of each pulmonary vein orifice. 
and in close relationship to the left pulmonary artery, to enter the most superior and lateral aspect of the LA near the left atrial appendage. The inferior PVs take a more direct and horizontal course to enter the most inferolateral aspect of the LA. ${ }^{1}$

\begin{tabular}{|c|c|}
\hline I. & Pulmonary vein varix \\
\hline II. & Supernumerary veins \\
\hline III. & Common trunk \\
\hline IV. & Single or multiple vein stenosis or atresia \\
\hline V. & $\begin{array}{l}\text { Anomalous pulmonary venous return } \\
\text { A. Partial anomalous pulmonary venous return } \\
\text { 1. Right lung: drainage to } \\
\text { a. Right superior vena cava } \\
\text { b. Right atrium } \\
\text { c. Coronary sinus } \\
\text { d. Azygos vein } \\
\text { e. Inferior vena cava } \\
\text { i. Scimitar syndrome } \\
\text { ii. Pseudoscimitar syndrome } \\
\text { 2. Left lung: drainage to } \\
\text { a. Vertical vein } \\
\text { b. Coronary sinus } \\
\text { B. Total anomalous pulmonary venous return } \\
\text { 1. Supracardiac } \\
\text { 2. Cardiac } \\
\text { 3. Infracardiac } \\
\text { 4. Mixed }\end{array}$ \\
\hline
\end{tabular}

\section{Pulmonary vein anomalies}

Pulmonary vein anatomy is more variable than pulmonary arterial anatomy, and developmental anomalies are common. The developmental anomalies include variations in number, stenosis and dilatations, and abnormal pulmonary-systemic connections as shown in Box 1., 2,5,6 The commonest anomalies are variations in number, either supernumerary veins or a common trunk. When variations occur, the right side tends to have accessory veins (one or more), and the left side tends to have convergent veins (a short or long common trunk) which drains into the LA. Marom et al. found that most patients $(71 \%)$ had two ostia on the right side for upper and lower lobe veins, but $28 \%$ had three to five ostia on the right side, which were because of one or two separate middle lobe vein ostia and $2 \%$ had a single venous ostium on the right side. Most patients $(86 \%)$ had two ostia on the left side for upper and lower lobe veins, but the remaining $14 \%$ had a single left ostium. ${ }^{7}$ Cronin et al. demonstrated that while the majority of patients, $82 \%$, had four PVs, with a superior and inferior ostium on the right and a superior and inferior ostium on the left, $9 \%$ had five veins, $4.5 \%$ had three veins, $3 \%$ had two anomalies and $0.5 \%$ had three anomalies. ${ }^{8}$ The commonest anomalies reported in the literature and in our cohort of patients are outlined in (Table 1).

TABLE 1: The commonest pulmonary vein anomalies.

\begin{tabular}{|c|c|c|c|}
\hline Anomaly & Classification of anomaly & Frequency in the literature $(\%)$ & Frequency in our cohort (\%) \\
\hline Middle lobe pulmonary vein draining directly to the left atrium & II. Supernumerary veins & $2-26$ & 11 \\
\hline Common left trunk & III. Common trunk & $2-25$ & 7 \\
\hline Accessory right inferior pulmonary vein & II. Supernumerary veins & $2-4$ & 3 \\
\hline Common right trunk & III. Common trunk & 1 & 1 \\
\hline Anomalous pulmonary venous return & $\begin{array}{l}\text { V. Anomalous pulmonary venous return } \\
\text { A. Partial anomalous pulmonary venous return } \\
\text { 1. Right lung: drainage to } \\
\text { a. Right superior vena cava }\end{array}$ & $0.1-0.7$ & 0.5 \\
\hline
\end{tabular}
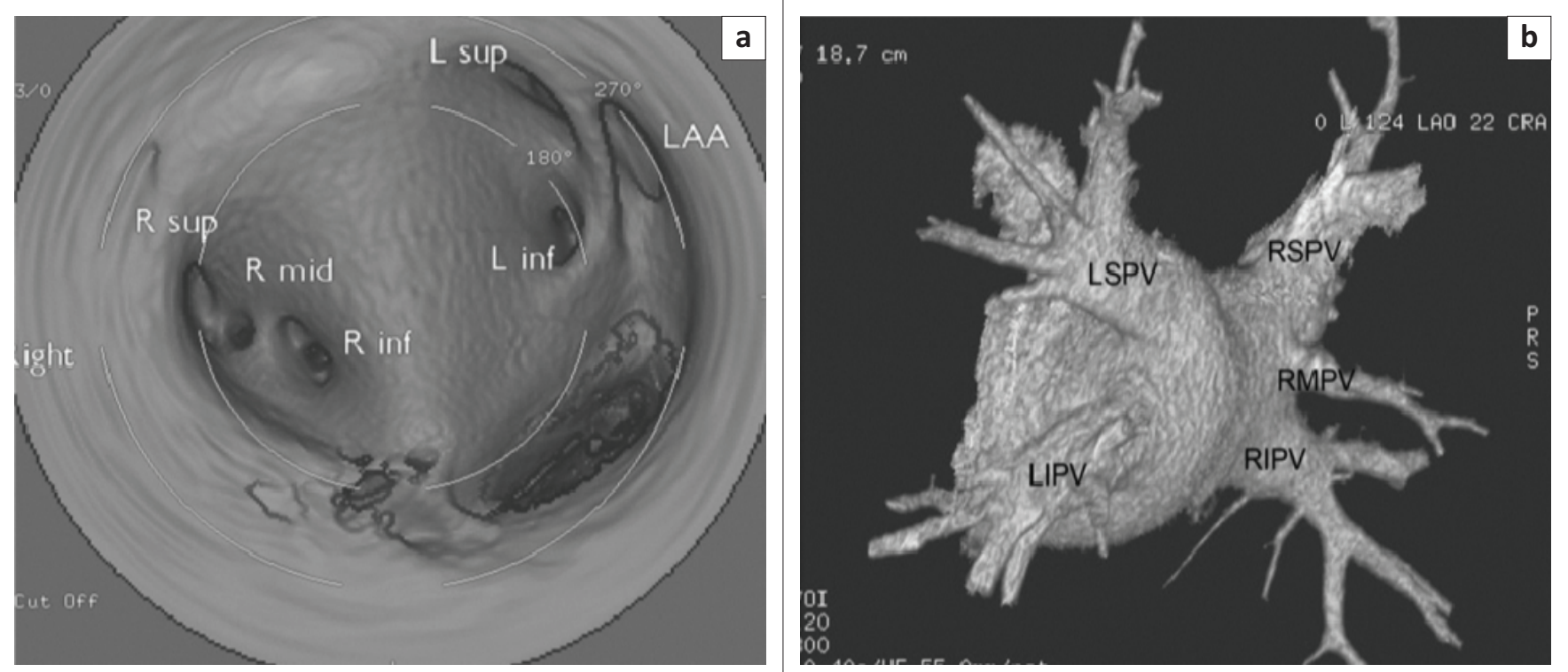

$R$ sup, right superior pulmonary vein; $R$ mid, right middle pulmonary vein; $R$ inf, right inferior pulmonary vein; $L$ sup, left superior pulmonary vein; $L$ inf, left inferior pulmonary vein; $L A A$, left atrial appendage; RSPV, right superior pulmonary vein; RMPV, right middle pulmonary vein; RIPV, right inferior pulmonary vein; LSPV, left superior pulmonary vein; LIPV, left inferior pulmonary vein.

FIGURE 2: Supernumerary veins in a 55-year-old man with atrial fibrillation. The middle lobe pulmonary vein has direct drainage into the left atrium: (a) The whole left atrial endocardial view with the right superior pulmonary vein ostium ( $R$ sup), right middle pulmonary vein draining directly in to the left atrium ( $R$ mid), right inferior pulmonary vein ( $R$ inf), left superior pulmonary vein ( $L$ sup), left inferior pulmonary vein ( $L$ inf) and left atrial appendage (LAA); (b) Three-dimensional model of the left atrium and pulmonary veins which shows the right superior pulmonary vein ostium (RSPV), middle lobe pulmonary vein ostium (RMPV), right inferior pulmonary vein ostium (RIPV), left superior pulmonary vein ostium (LSPV) and left inferior pulmonary vein ostium (LIPV). 

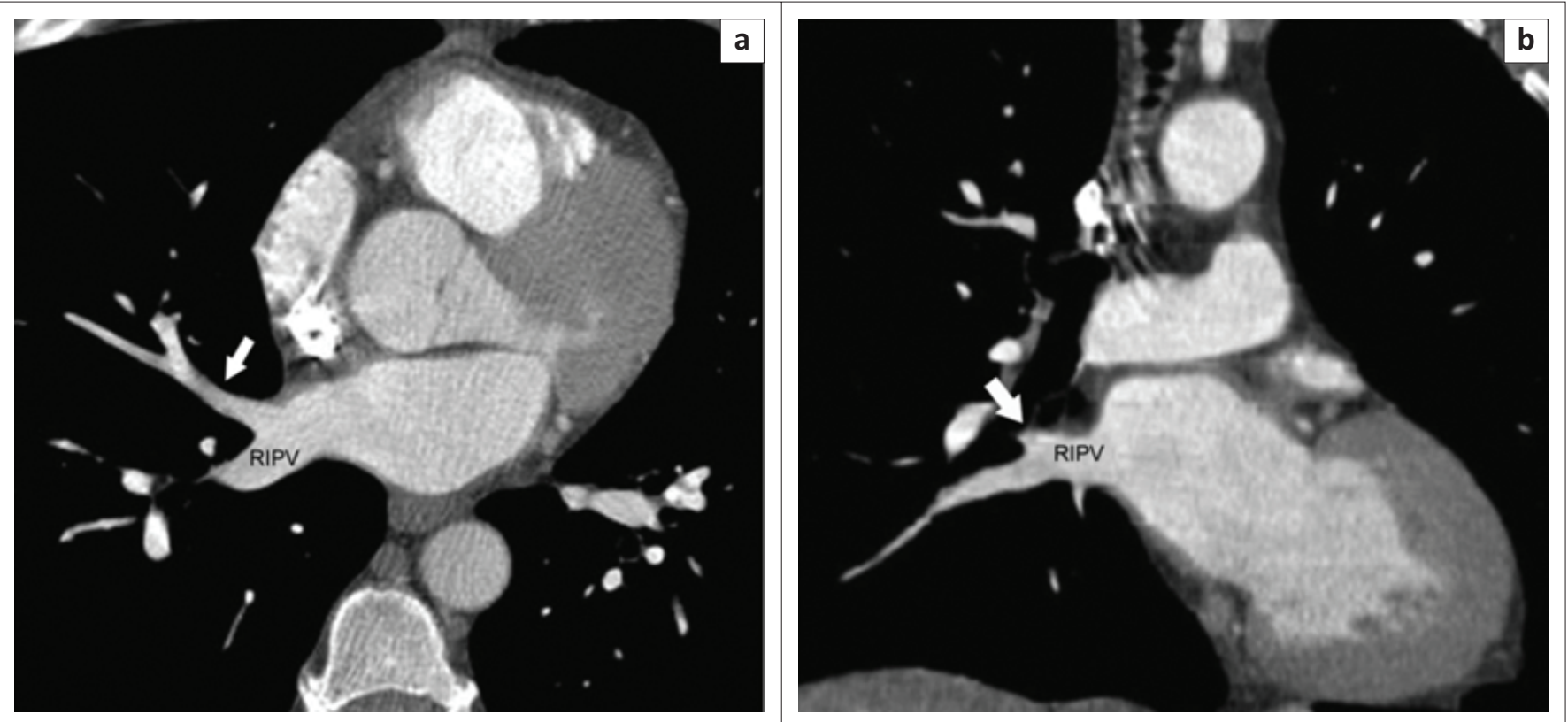

RIPV, right inferior pulmonary vein.

FIGURE 3: The (a) middle lobe pulmonary vein (arrow) draining directly into the right inferior pulmonary vein; (b) multiplanar reformat.

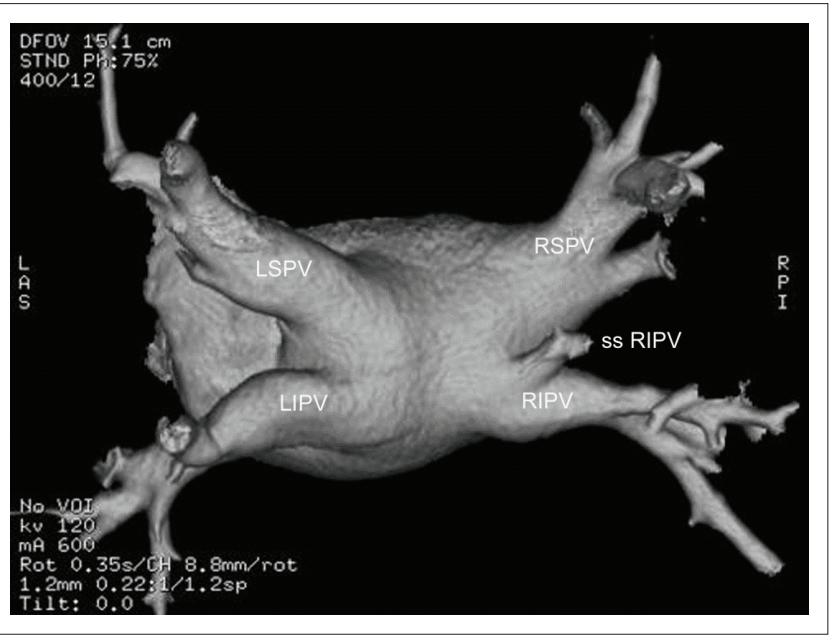

RSPV, right superior pulmonary vein; sS RIPV, superior segment right inferior pulmonary vein RIPV, right inferior pulmonary vein; LSPV, left superior pulmonary vein; LIPV, left inferior pulmonary vein.

FIGURE 4: Supernumerary vein in another patient with atrial fibrillation. A vein draining the superior segment of the right lower lobe pulmonary vein draining directly into the left atrium, 3D view of the left atrium shows the right superior pulmonary vein (RSPV), the superior segment of the right lower lobe pulmonary vein (ss RIPV), the right inferior pulmonary vein proper (RIPV), the left superior pulmonary vein (LSPV) and the left inferior pulmonary vein (LIPV).

\section{Pulmonary vein varix}

Pulmonary vein varix is a dilated PV that may be either congenital or acquired..$^{9}$ Its appearance can simulate a lung nodule on chest radiographic images or on contrast material enhanced chest $\mathrm{CT} .{ }^{10} \mathrm{PV}$ varix has not been identified in any of our patients imaged with pre-procedure mapping CT examinations.

\section{Supernumerary veins}

Supernumerary or accessory veins are common. An accessory vein has its own independent atriopulmonary venous junction separate from the superior and inferior PVs. Supernumerary veins result from excessive resorption, and most commonly involve a third vein on the right, which usually drains the middle lobe (Figure 2). It is reported to be found in, approximately, $1.6 \%-26 \%$ of individuals. ${ }^{2,7,8,11,12}$ Tsao et al. in a series of 43 cases reported that the right middle lobe vein may drain directly into the LA in $23 \%$ of patients, share a common ostium to the proximal RSPV in $69 \%$ of patients and share a common ostium to the proximal right inferior pulmonary vein (RIPV) in $8 \%$ of patients. ${ }^{12}$ In another review of 200 consecutive patients referred for CT imaging prior to a radiofrequency ablation procedure for $\mathrm{AF}$, the authors found that in $83.5 \%$ of patients the middle lobe pulmonary vein (MLPV) drained to the RSPV, in $11 \%$ of patients it drained into the LA (Figure 2) and in 5.5\% of patients it drained into the RIPV (Figure 3). ${ }^{8}$ The ostial diameter of the right middle PV is usually significantly smaller than the four main PVs. ${ }^{8}$ Another common supernumerary variant is an accessory vein draining the superior segment of the right lower lobe directly into the LA (Figure 4). When present, an accessory PV has a significantly smaller diameter, on average $8 \mathrm{~mm}$ compared to the main PVs, $16 \mathrm{~mm}-17 \mathrm{~mm} .^{8}$ Left middle veins are rare occurring in $0.1 \%-0.5 \%$ of patients in our experience (Figure 5).

Multiples of supernumerary veins may also occur including two middle lobe veins (one draining the medial segment and the other draining the lateral segment of the middle lobe) directly into the LA (Figure 6). Combinations of supernumerary veins may also be seen, including two accessory PVs, with one accessory vein draining the middle lobe and another vein draining the superior segment of the right lower lobe directly to the LA. Combinations and multiples of supernumerary veins may also occur. 

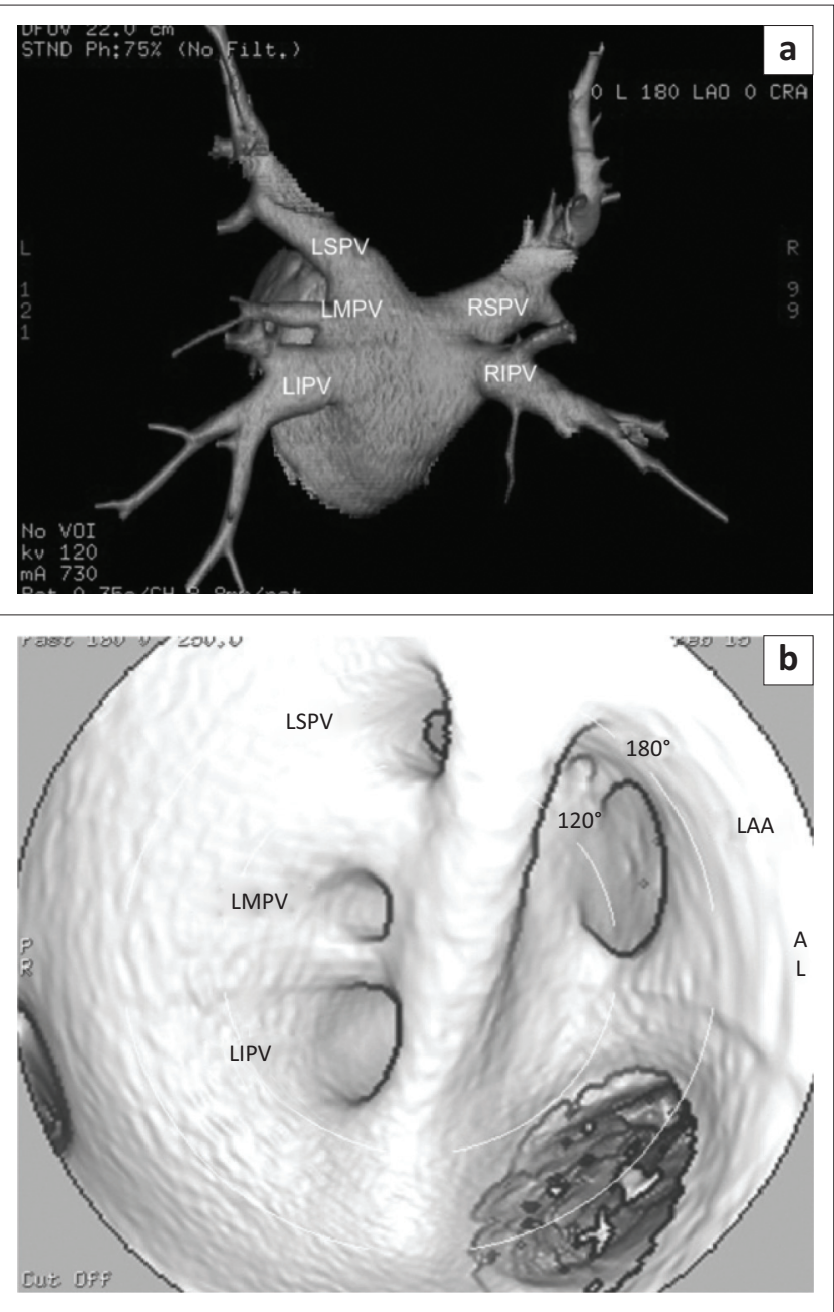

LSPV, left superior pulmonary vein; LIPV, left inferior pulmonary vein; RSPV, superio segment right inferior pulmonary vein; RIPV, right inferior pulmonary vein; LMPV, left middle pulmonary vein; LAA, left atrium appendage.

FIGURE 5: Supernumerary vein in a 52-year-old man with atrial fibrillation, with a left middle pulmonary vein draining the lingula directly into the left atrium: (a) Three-dimensional model of the left atrium and pulmonary veins, which shows the left superior pulmonary vein (LSPV), left accessory pulmonary vein draining the lingula directly to the left atrium. This is equivalent to an accessory middle lobe vein on the right. This is labelled as the left middle pulmonary vein (LMPV). Left inferior pulmonary vein (LIPV), right superior pulmonary vein (RSPV) and right inferio pulmonary vein (RIPV); (b) The left atrial endocardial view which shows the left superior pulmonary vein ostium (LSPV), left middle pulmonary vein ostium (LMPV), left inferior pulmonary vein ostium (LIPV) and left atrium appendage (LAA).

These include direct drainage of the middle lobe into the LA with three RIPVs (Figure 7). Another variation, with two middle lobe veins (one draining the medial segment and the other draining the lateral segment of the middle lobe) draining directly into the LA and an accessory vein draining the superior segment of the right lower lobe in addition to the RIPV (Figure 8).

\section{Common trunk}

A common trunk occurs when the superior and inferior veins converge to form a single atriopulmonary venous junction. A common ostium for the superior and inferior veins is reported to occur in approximately $2.4 \%-25 \%$ of individuals. ${ }^{17,8,9,11,13,14}$ Most are on the left (Figure 9), and a
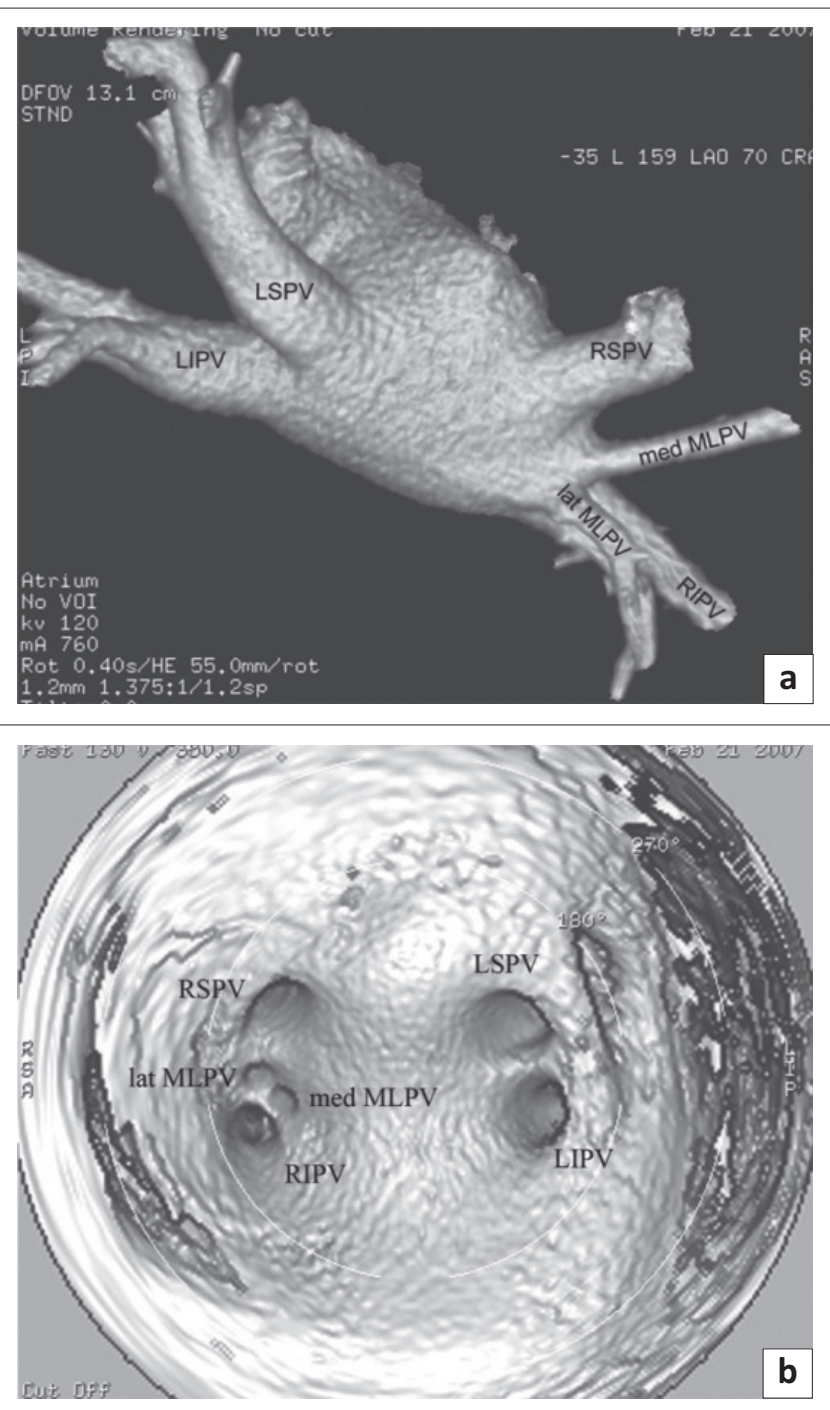

LSPV, left superior pulmonary vein; LIPV, left inferior pulmonary vein ostium; RSPV right superior pulmonary vein ostium; med MLPV, middle lobe pulmonary vein ostium draining the medial segment of the middle lobe; lat MLPV, middle lobe pulmonary vein ostium draining the lateral segment of the middle lobe; RIPV, right inferior pulmonary vein.

FIGURE 6: Multiples of supernumerary veins in another patient with atrial fibrillation, with two middle lobe veins (one draining the medial segment and the other draining the lateral segment of the middle lobe) draining directly into the left atrium. Left superior pulmonary vein (LSPV), left inferior pulmonary vein ostium (LIPV), right superior pulmonary vein ostium (RSPV), middle lobe pulmonary vein ostium draining the medial segment of the middle lobe (med MLPV), middle lobe pulmonary vein ostium draining the lateral segment of the middle lobe (lat MLPV) and right inferior pulmonary vein (RIPV): (a) Threedimensional model. (b) Endocardial view.

single common left vein is much more common than a common right vein (Figure 10). Bilateral common trunks have not been described in the literature, and no patient in our experience has had bilateral common trunks. Embryologically, this is because of incomplete resorption of the primitive common PV. Marom et al. found a left common trunk in $14 \%$ of subjects while. ${ }^{7}$ Cronin et al. found a single common left PV trunk in $6.5 \%$, and a single common right PV trunk in two patients $(1 \%){ }^{8}$ When present, a common PV trunk has a significantly larger diameter than normal PVs. Cronin et al. also found that a common trunk (mean diameter $24 \mathrm{~mm}$ ) was statistically larger than the mean diameter of the superior or inferior PVs, and mean right-sided or left-sided PV diameters. 

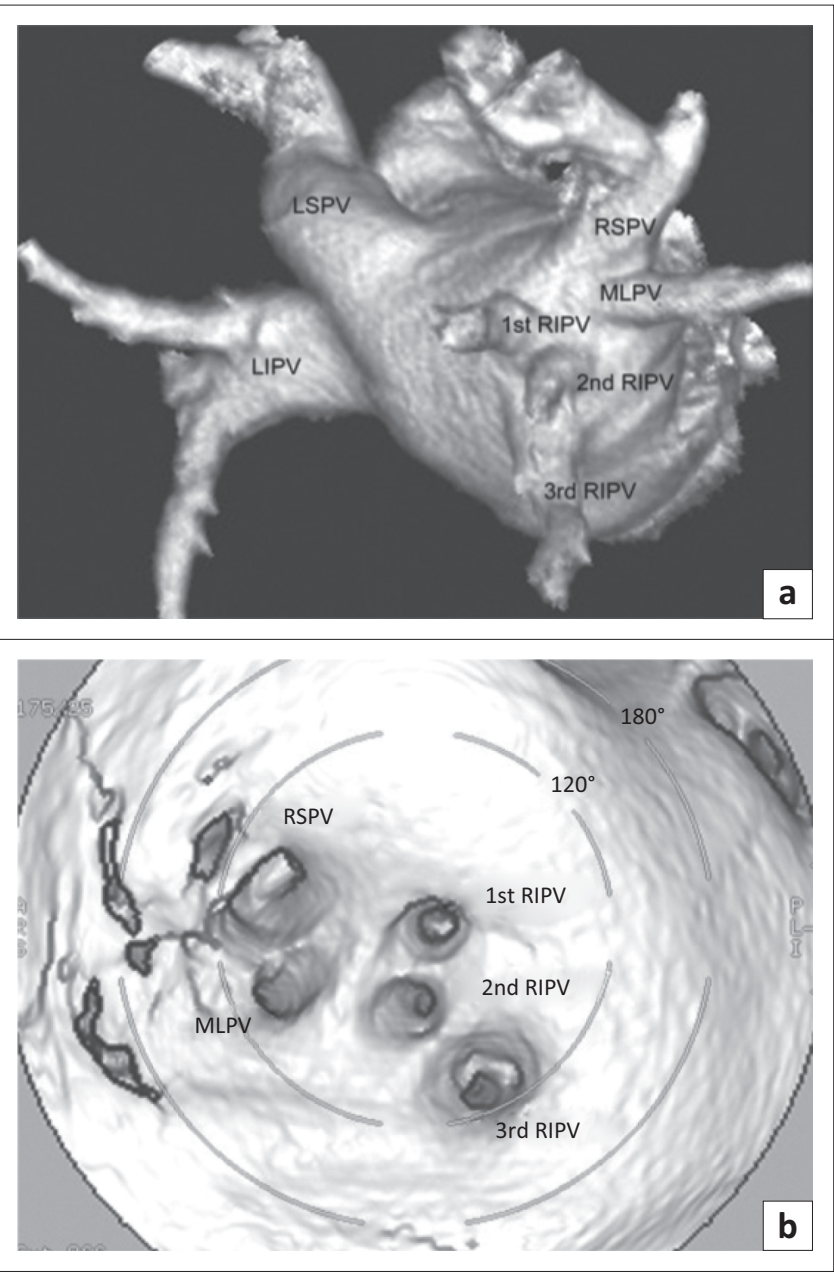

LSPV, left superior pulmonary vein; LIPV, left inferior pulmonary vein; RSPV, right superio pulmonary vein; MLPV, middle lobe pulmonary vein; 1 st RIPV, first right inferior pulmonary vein; 2 nd RIPV, second right inferior pulmonary vein; 3rd RIPV, third right inferior pulmonary vein.

FIGURE 7: Combination of supernumerary veins in a 48-year-old man prior to a radiofrequency ablation procedure for atrial fibrillation: (a) Three-dimensional model. There is direct drainage of the middle lobe into the left atrium and three right inferior pulmonary veins. Left superior pulmonary vein (LSPV), left inferior pulmonary vein (LIPV), right superior pulmonary vein (RSPV), middle lobe pulmonary vein (MLPV), first right inferior pulmonary vein (1st RIPV), second right inferior pulmonary vein (2nd RIPV) and third right inferior pulmonary vein (3rd RIPV). (b) Endocardial view. Right superior pulmonary vein (RSPV), middle lobe pulmonary vein (MLPV), first right inferior pulmonary vein (1st RIPV), second right inferior pulmonary vein (2nd RIPV) and third right inferior pulmonary vein (3rd RIPV).

A common trunk between the right inferior and left inferior pulmonary veins (LIPVs) has been reported. Combinations of supernumerary veins with a common trunk are noted (Figure 11).

\section{Single or multiple vein stenosis or atresia}

Congenital PV stenosis usually involves multiple veins, is bilateral, is of varying degree of severity and occurs at the ostium, though may extend peripherally. ${ }^{2,12,15,16,17}$ The exact mechanism is unknown. The stenosis can result in asymmetric vascular distribution and pulmonary edema and Kerley B lines. The prognosis is poor and, therefore, congenital stenoses are seen in the paediatric rather than the adult population. ${ }^{2}$ While non-significant $(<50 \%$ stenosis $)$ diffuse or focal stenoses can rarely be seen on pre-procedure CT studies, significant single or multiple PV stenosis or
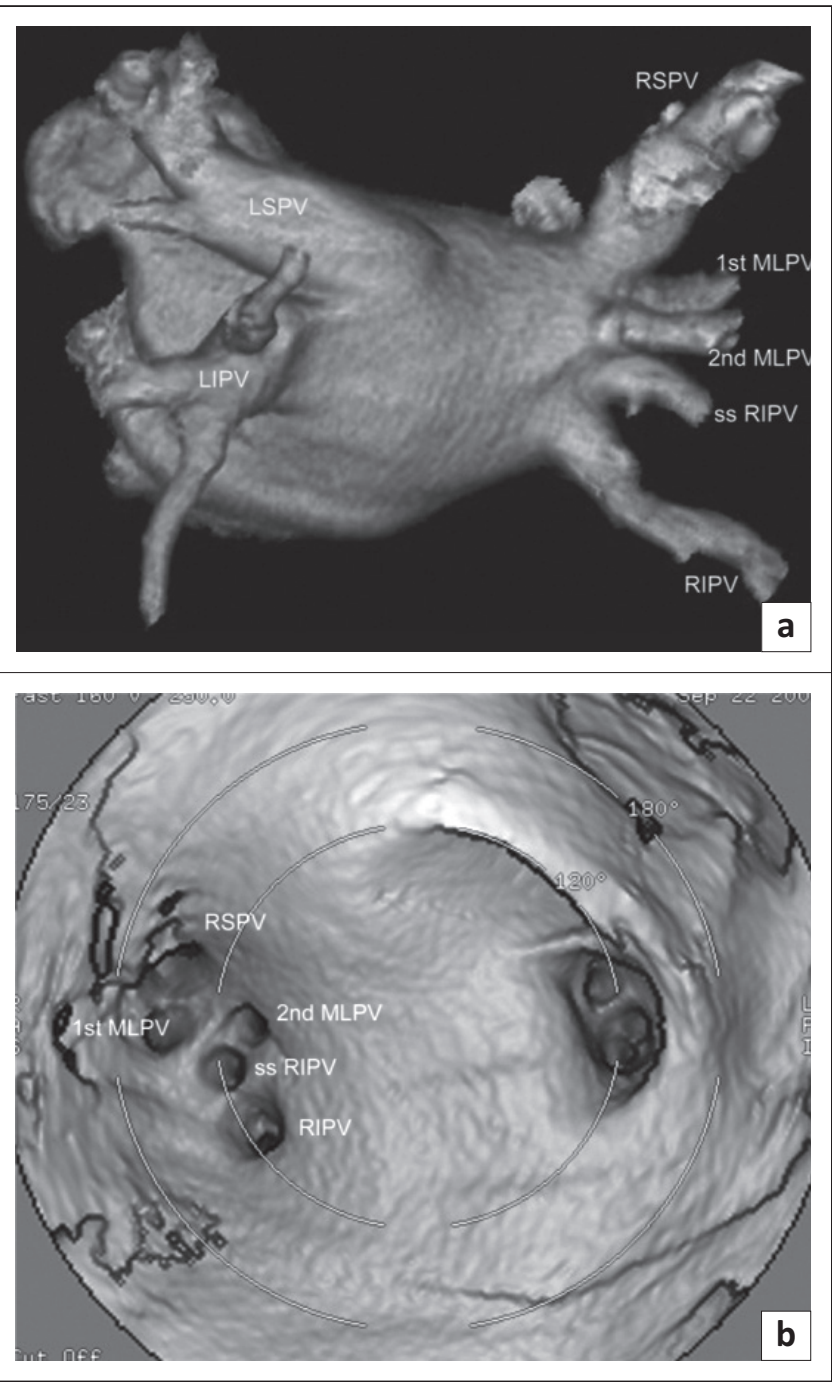

LSPV, left superior pulmonary vein; LIPV, left inferior pulmonary vein; LA, left atrium; RSPV, right superior pulmonary vein ostium; 1st MLPV, first middle lobe pulmonary vein ostium; 2nd MLPV, second middle lobe pulmonary vein ostium; RIPV, right inferior pulmonary vein; ss RIPV, superior segment right inferior pulmonary vein.

FIGURE 8: Combination of supernumerary veins in another patient with atrial fibrillation, with two middle lobe veins draining directly into the left atrium, and an accessory vein draining the superior segment of the right lower lobe in addition to the right inferior pulmonary vein: (a) Three-dimensional model. Left superior pulmonary vein (LSPV), left inferior pulmonary vein (LIPV), right superior pulmonary vein ostium (RSPV), first middle lobe pulmonary vein ostium (1st MLPV), second middle lobe pulmonary vein ostium (2nd MLPV), right inferior pulmonary vein (RIPV) and accessory right inferior pulmonary vein draining the superior segment of the right lower lobe (ss RIPV); (b) Endocardial view. Right superior pulmonary vein ostium (RSPV), first middle lobe pulmonary vein ostium (1st MLPV), second middle lobe pulmonary vein ostium (2nd MLPV), right inferior pulmonary vein (RIPV) and accessory right inferior pulmonary vein draining the superior segment of the right lower lobe (ss RIPV).

atresia has not been identified in any of our patients preprocedure. PV stenosis is a recognised complication of the PV ablation procedure (Figure 12). These stenoses are usually mild; (Figure 12a). Rarely post procedure stenoses can be severe requiring treatment with angioplasty or stenting, (Figure 12b). ${ }^{11}$

\section{Anomalous pulmonary venous return}

A variety of anomalous pulmonary and systemic connections exists. Drainage can be either partial or total. Partial anomalous pulmonary venous return (PAPVR) has an incidence of approximately $0.5 \%$, involves the right lung 

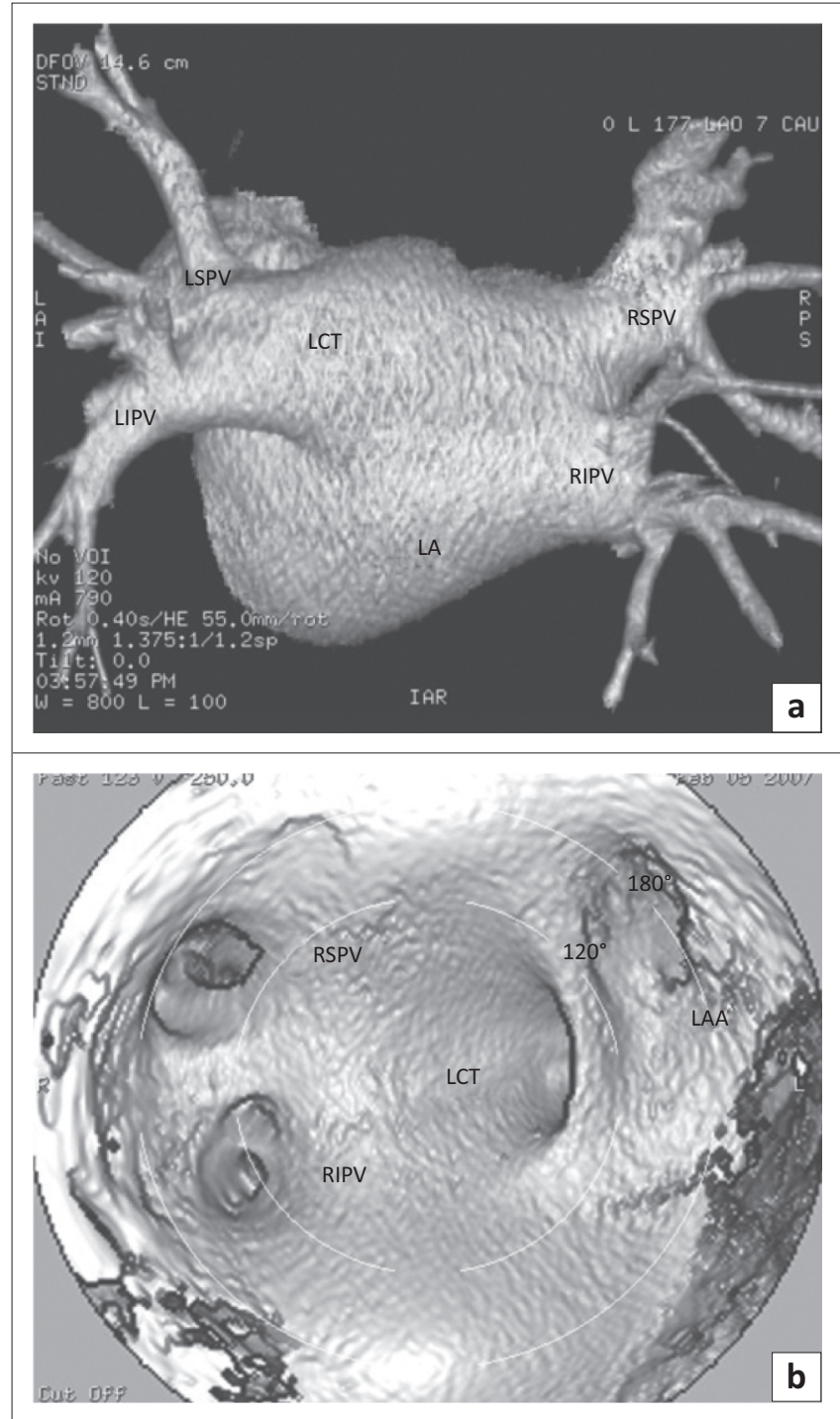

LSPV, left superior pulmonary vein; LIPV, left inferior pulmonary vein; LCT, left common trunk; RSPV, right superior pulmonary vein; RIPV, right inferior pulmonary vein; LA, left atrium; LAA, left atrial appendage.

FIGURE 9: Common left trunk in a 53-year-old woman with atrial fibrillation: (a) Three-dimensional image. Left superior pulmonary vein (LSPV), left inferior pulmonary vein (LIPV), left common trunk (LCT), right superior pulmonary vein (RSPV), right inferior pulmonary vein (RIPV), left atrium (LA); (b) Threedimensional model. Right superior pulmonary vein (RSPV), right inferior pulmonary vein (RIPV), left common trunk (LCT) and left atrial appendage (LAA).

more frequently than the left lung and is usually hemodynamically insignificant but may be hemodynamically significant when associated with congenital heart disease or Scimitar syndrome. ${ }^{18,19,20,21}$ All PAPVRs are left-to-right shunts, but the shunt is usually hemodynamically insignificant. Anomalous veins of the right lung most often drain the right upper lobe to the SVC, and this is the most frequent isolated PAPVR overall. This is usually associated with a sinus venosus type of atrial septal defect. ${ }^{10} \mathrm{~A}$ PAPVR draining into veins below the diaphragm i.e. the IVC, portal, hepatic, or other, is association with hypoplasia of the right lung and has been called the scimitar, venolobar or hypogenetic lung syndrome. The spectrum of anomalies and prognosis is variable and depends on the size of the left-to-right shunt. Anomalous veins of the left lung most often drain the left upper lobe, and this is the most frequent
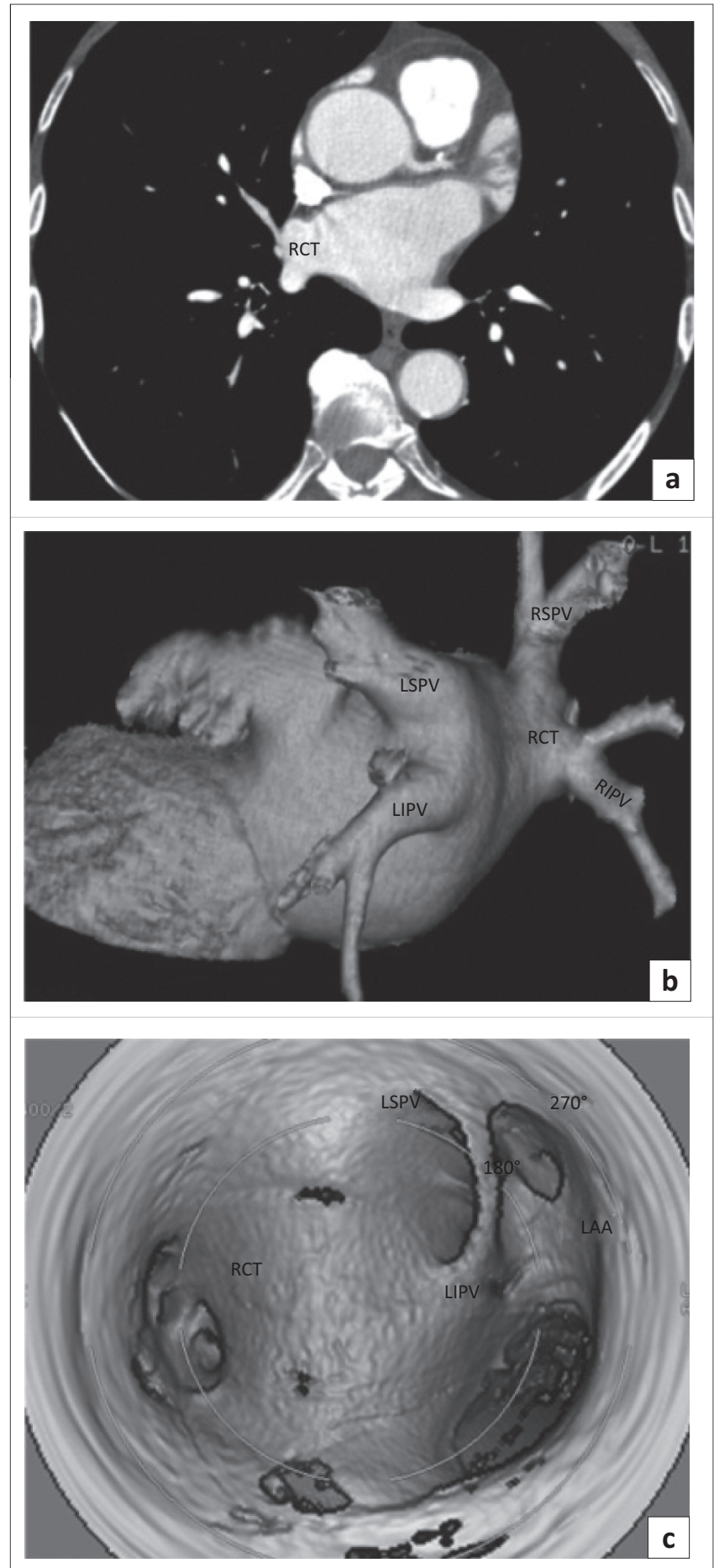

RSPV, right superior pulmonary vein; RIPV, right inferior pulmonary vein; RCT, right common trunk; LSPV, left superior pulmonary vein; LIPV, left inferior pulmonary vein; LAA, left atrial appendage.

FIGURE 10: Common right trunk in another patient with atrial fibrillation: (a) Axial image. Right superior pulmonary vein (RSPV); (b) Three-dimensional model. Right superior pulmonary vein (RSPV), right inferior pulmonary vein (RIPV), right common trunk (RCT), left superior pulmonary vein (LSPV) and left inferior pulmonary vein (LIPV); (c) Endocardial view. Right common trunk (RCT), left superior pulmonary vein (LSPV), left inferior pulmonary vein (LIPV) and left atrial appendage (LAA).

isolated PAPVR on the left. ${ }^{10}$ Distinction should be made between a left SVC and an anomalous vertical PV. An anomalous pulmonary vertical vein drains some or all of the left pulmonary venous drainage, ascends superiorly, and drains into the left brachiocephalic vein. The left SVC drains into the heart. 


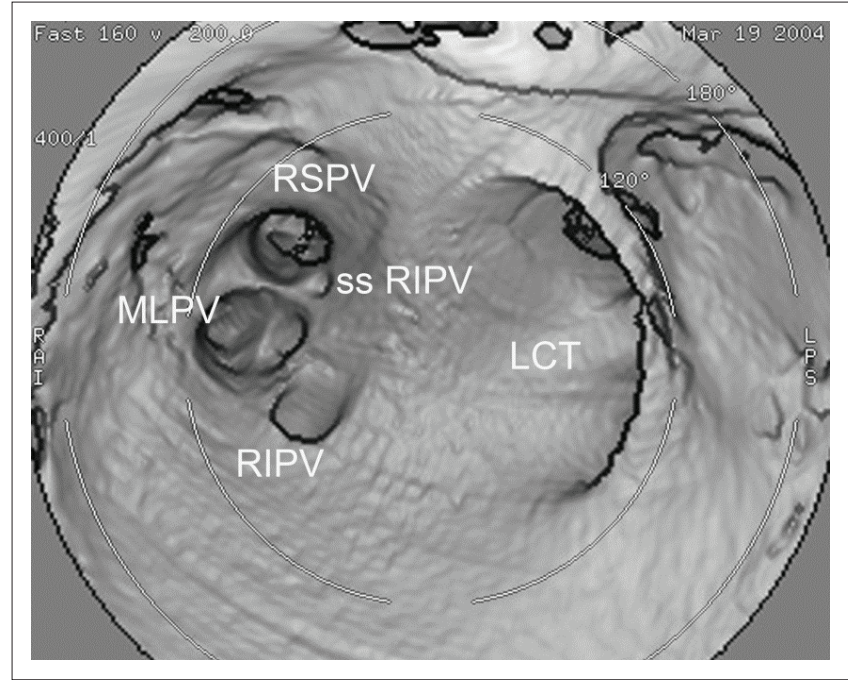

RSPV, right superior pulmonary vein; MLPV, middle lobe pulmonary vein; RIPV, right inferio pulmonary vein; sS RIPV, superior segment right inferior pulmonary vein; LCT, left common trunk. FIGURE 11: Combination of supernumerary veins with a common trunk. There is a middle lobe vein draining directly into the left atrium and an accessory vein draining the superior segment of the right lower lobe in addition to the right inferior pulmonary vein and common left trunk, endocardial view. Right superior pulmonary vein (RSPV), middle lobe pulmonary vein (MLPV), right inferior pulmonary vein (RIPV), accessory right inferior pulmonary vein draining the superior segment of the right lower lobe (sS RIPV) and left common trunk (LCT)
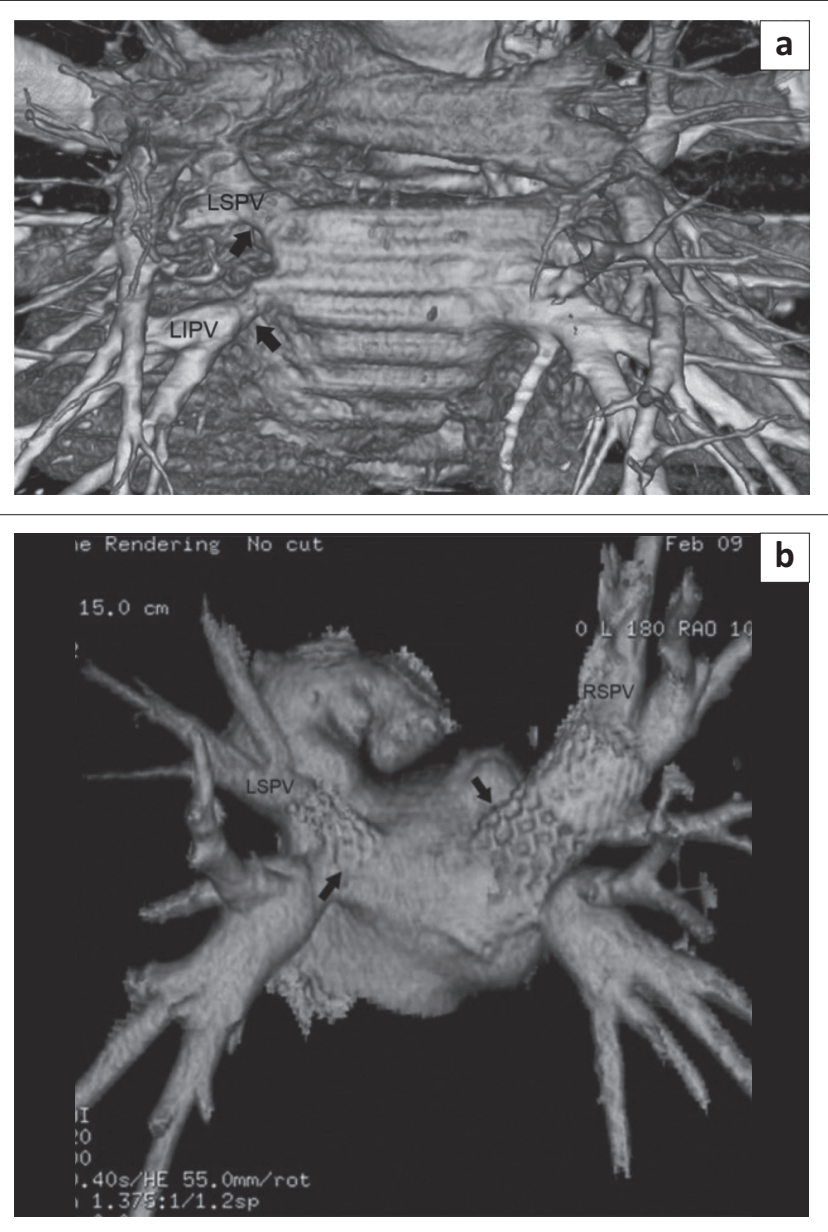

LSPV, left superior pulmonary vein; RSPV, right superior pulmonary vein.

FIGURE 12: (a) A three-dimensional model of a patient: post radiofrequency ablation for atrial fibrillation showing minor stenoses in the left superior and left inferior pulmonary veins (arrow); (b) A three-dimensional model of another patient: post ablation shows stenoses in the right and left superior pulmonary veins severe enough to require stent insertion (arrow).
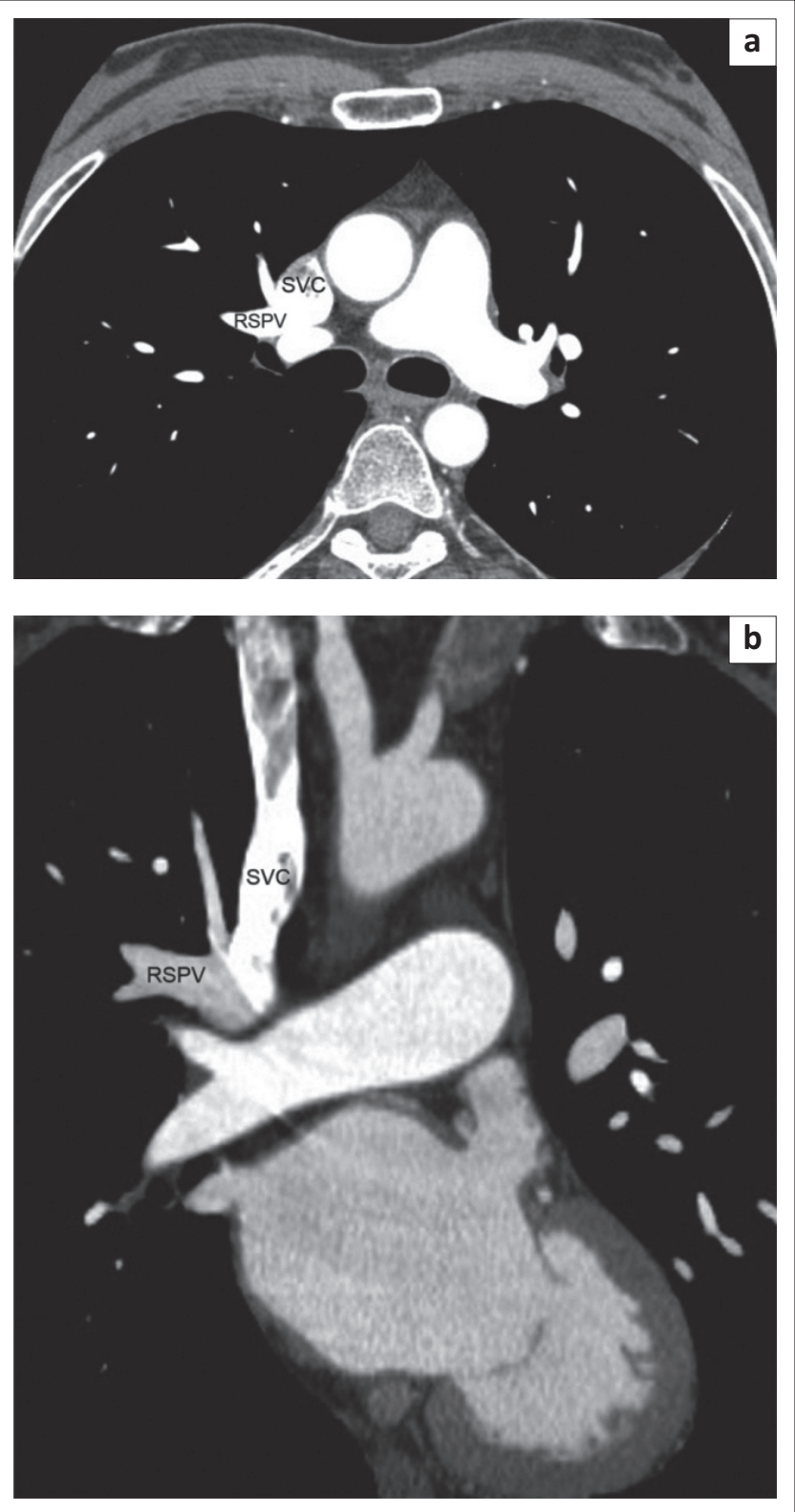

SVC, Superior vena cava; RSPV, right superior pulmonary vein

FIGURE 13: Partial anomalous pulmonary venous return in a 49-year-old man. The right superior pulmonary drains directly into the superior vena cava (SVC): (a) Axial image; (b) Oblique coronal image.

In our experience, we have had three patients with right superior PAPVR, two patients with direct drainage of the RSPV to the SVC (Figure 13), and one with drainage of the RSPV and an accessory RIPV to the SVC via the azygos vein (Figure 14). We have had one further patient with a right inferior PAPVR with drainage of the RIPV to the IVC (Figure 15). We have also had two patients with a left superior PAPVR, with the LSPV draining to the left brachiocephalic vein via a vertical vein.

\section{Anomalous pulmonary venous return}

With total anomalous pulmonary venous return (TAPVR), there is obligatory interatrial communication through an atrial septal defect or patent foramen ovale. Pulmonary vascularity may be increased and there may be cyanosis. ${ }^{10}$ These abnormal pulmonary-systemic venous connections are 


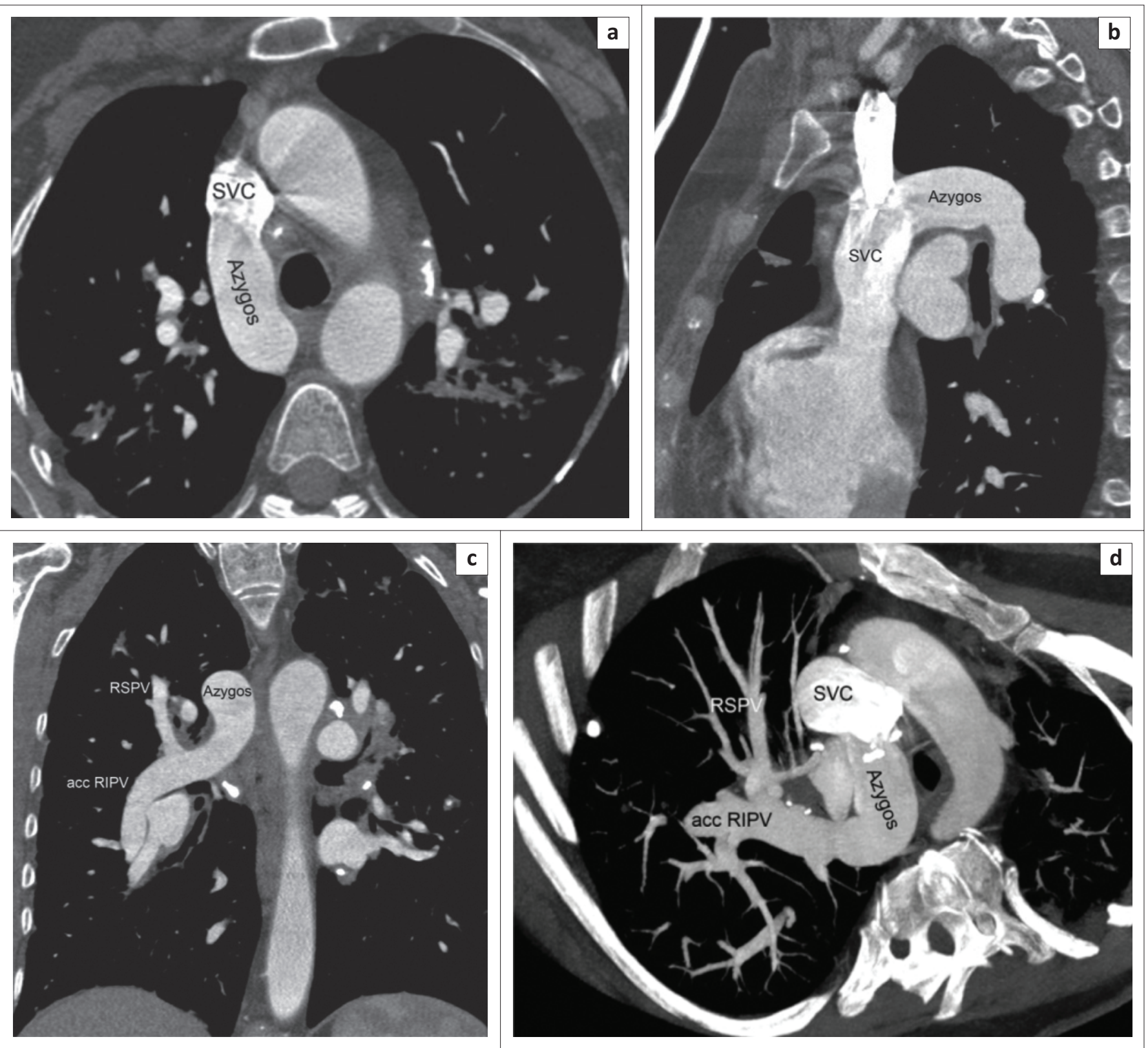

SVC, Superior vena cava; RSPV, right superior pulmonary vein.

FIGURE 14: Partial anomalous pulmonary venous return in a 51-year-old woman. The right superior pulmonary vein and an accessory right inferior pulmonary vein drain into the superior vena cava (SVC) via the azygos vein: (a) Axial image; (b) Sagittal image; (c) Coronal image; (d) Oblique axial image.

best classified based on their embryologic derivation and the anatomy of the anomalous connection. Based on this classification, four types are described. (1) Supracardiac: (a) Into derivatives of the right cardinal system (SVC or azygous vein); (b) Into derivatives of the left cardinal system (a persistent left SVC, vertical vein or left brachiocephalic vein). (2) Cardiac: (a) Into derivatives of the left cardinal system (the coronary sinus); (b) Into the right atrium. (3) Infracardiac: (a) Into the unbilicovitelline system (the portal vein or ductus venosus); (b) Into the IVC. (4) Mixed: A combination of two or more of the anomalies described above may occur. ${ }^{4}$ The supracardiac drainage type of TAPVR has drainage to a left vertical vein that extends to the left brachiocephalic vein. The infracardiac drainage type of TAPVR, which is the least common type, is associated with severe congestive heart failure. TAPVR is associated with asplenia (right isomerism). ${ }^{10}$
We have not identified any patients with TAPVR on pre-ablation mapping CT.

\section{Cor triatriatum}

Cor triatriatum is a congenital cardiac malformation because of an abnormal connection between the common $\mathrm{PV}$ and the atria. It is characterised by the presence of a fibromuscular membrane separating the LA into two parts: The upper of the chambers communicates with the PVs and the lower with the mitral valve containing the left atrial appendage. ${ }^{22}$ With Cor triatriatum there appears to be a double atrium, however, the accessory atrium is in fact a dilated primitive common PV which has failed to resorb. The dilatation is because of stenosis of the primitive common PV at the level of the LA. It has no clear gender 


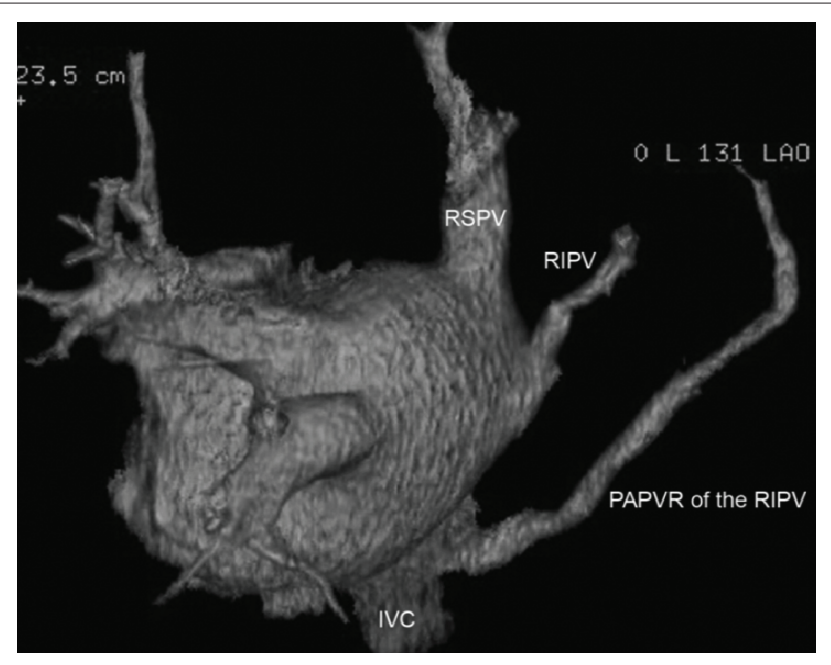

RIPV, Right inferior pulmonary vein; PAPVR, partial anomalous pulmonary venous return IVC, inferior vena cava.

FIGURE 15: Partial anomalous pulmonary venous return in a 62-year-old man One right inferior pulmonary vein drains into the left atrium, and another right inferior pulmonary vein drains into the IVC. Right inferior pulmonary vein (RIPV) partial anomalous pulmonary venous return (PAPVR of the RIPV) and inferior vena cava (IVC). Three-dimensional model. predilection. There is an association with other cardiac defects in up to $50 \%$ of cases, the most frequent being atrial septal defects and the second most frequent, anomalous PV return. ${ }^{22,23}$ Severity is variable and clinical manifestations may occur within the first few days of life or be delayed until adulthood depending on severity of PV hemodynamic obstruction. ${ }^{2}$ The natural history of this defect is dependent on the size of the orifice in the membrane. Infants are critically ill and have a poor survival rate without early treatment if ostia are small or not present. If the connection is large or is associated with an atrial septal defect, patients in childhood or young adulthood present with a clinical picture mimicking mitral stenosis with pulmonary hypertension. Appearance in adulthood is well-documented ${ }^{22}$ and usually corresponds to patients with an unrecognised non-obstructive Cor triatriatum because of multiple or a large fenestration in the left atrial membrane. ${ }^{22}$ We have found two patients with incidental unrecognised non-obstructive Cor triatriatum (Figure 16).
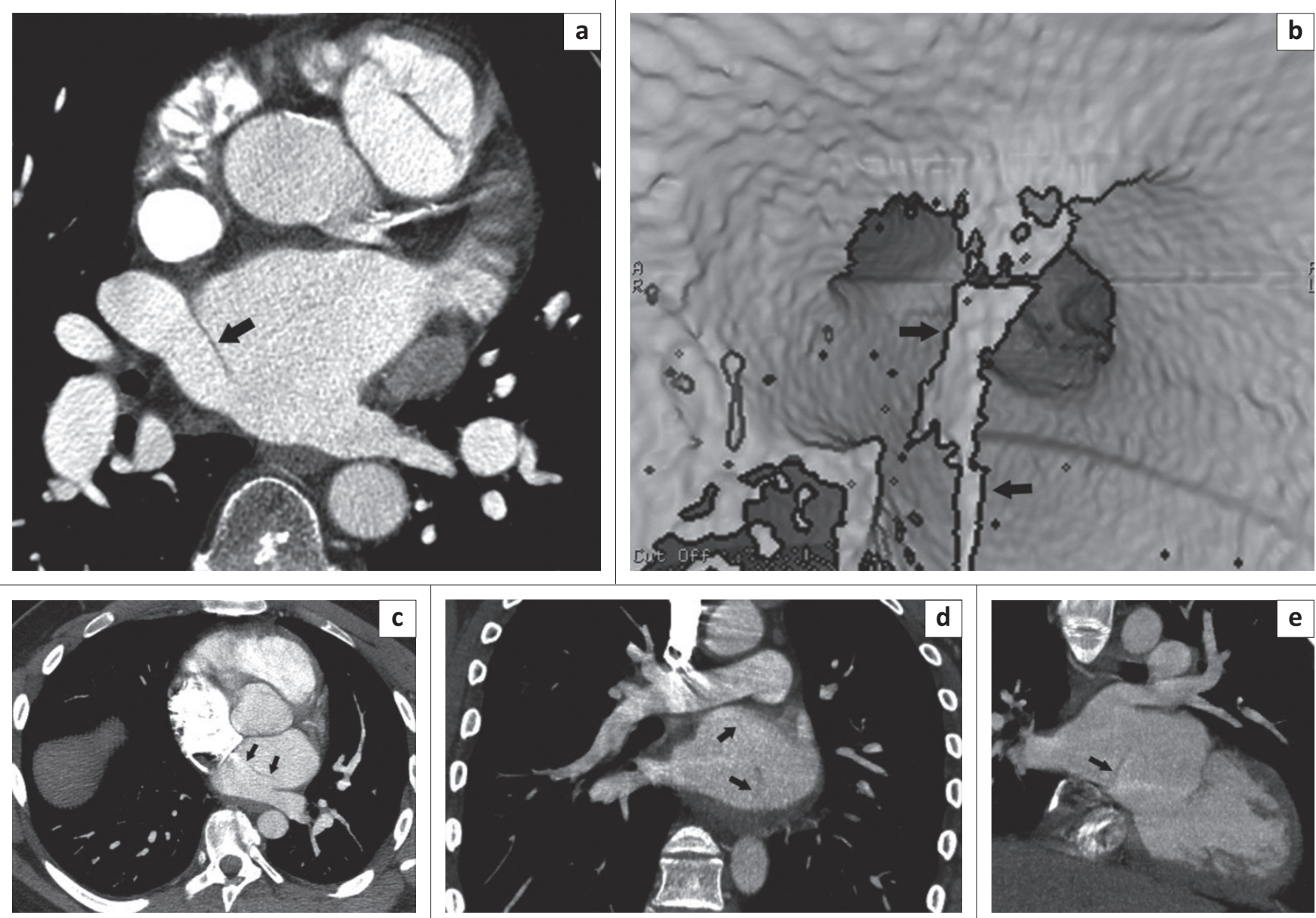

FIGURE 16: A fibromuscular membrane (arrow) separating the left atrium into two parts: the upper of the chambers communicates with the pulmonary veins and the lower with the mitral valve containing the left atrial appendage: (a) Axial image; (b) Endocardial view shows the fibromuscular membrane separating the left atrium into two parts. The lower row of images shows non-obstructive Cor triatriatum in another patient, a 28-year-old man with atrial fibrillation, fibromuscular membrane (arrow); (c) Axial image; (d) Oblique axial image; (e) Coronal image. 


\section{Conclusion}

Multidetector CT elegantly renders the pulmonary venous anatomy. With increasing numbers of radiofrequency ablation procedures being performed, there is now a greater emphasis on pre-procedure imaging to delineate this anatomy. Using thin collimation MDCT, the common anomalies of the PVs can be identified. The commonest anomalies are supernumerary or accessory veins (on the right) and a (left) common trunk. More rarely, PAPVR and Cor triatriatum are seen, and rarest of all are TAPVR, PV varix and single or multiple vein stenosis or atresia.

\section{Acknowledgements Competing interests}

The authors declare that they have no financial or personal relationships, which may have inappropriately influenced them in writing this article.

\section{Authors' contributions}

P.C. and A.M.K. contributed images. The text was written by P.C., with contributions from A.M.K. P.C. and A.M.K. were responsible for drafting the manuscript, which was critically reviewed by P.C. and A.M.K.

\section{References}

1. Cronin $P$, Sneider MB, Kazerooni EA, et al. MDCT of the left atrium and pulmonary veins in planning radiofrequency ablation for atrial fibrillation: A how-to guide. Am J Roentgenol. 2004;183(3):767-778. https://doi.org/10.2214/ajr.183.3. 1830767

2. Budorick NE, McDonald V, Flisak ME, Moncada RM. The pulmonary veins. Semin Roentgenol. 1989;24(2):127-140. https://doi.org/10.1016/0037-198X(89)90034-5

3. Herlong JR, Jaggers JJ, Ungerleider RM. Congenital heart surgery nomenclature and database project: Pulmonary venous anomalies. Ann Thorac Surg. 2000;69(Suppl 4):S205-S235. https://doi.org/10.1016/S0003 4975(99)01237-0

4. Healey JE. Anatomical survey of anomalous pulmonary veins: Their clinica significance. J Thor Surg. 1952;23:433-444.

5. Davis SD, Umlas SL. Radiology of congenital abnormalities of the chest. Curr Opin Radiol. 1992;4(5):25-35.
6. Alton H. Pulmonary vascular imaging. Paediatr Respir Rev. 2001;2(3):227-237. https://doi.org/10.1053/prrv.2001.0145

7. Marom EM, Herndon JE, Kim YH, McAdams HP. Variations in pulmonary venous drainage to the left atrium: Implications for radiofrequency ablation. Radiology. 2004;230(3):824-829. https://doi.org/10.1148/radiol.2303030315

8. Cronin P, Kelly AM, Desjardins B, et al. Normative analysis of pulmonary vein drainage patterns on multidetector CT with measurements of pulmonary vein ostial diameter and distance to first bifurcation. Acad Radiol. 2007;14(2):178-188. https://doi.org/10.1016/j.acra.2006.11.004

9. Vanherreweghe $E$, Rigauts $H$, Bogaerts $Y$, Meeus L. Pulmonary vein varix: Diagnosis with multi-slice helical CT. Eur Radiol. 2000;10:1315-1317. https://doi. org/10.1007/s003300000381

10. Demos TC, Posniak HV, Pierce KL, Olson MC, Muscato M. Venous anomalies of the thorax. AJR Am J Roentgenol. 2004;182(5):1139-1150. https://doi.org/10.2214/ ajr.182.5.1821139

11. Scharf C, Sneider M, Case I, et al. Anatomy of the pulmonary veins in patients with atrial fibrillation and effects of segmental ostial ablation analyzed by computed
tomography. J Cardiovasc Electrophysiol. 2003;14:150-155. https://doi. tomography. J Cardiovasc Electrop
org/10.1046/j.1540-8167.2003.02444.x

12. Tsao HM, Wu MH, Yu WC, et al. Role of right middle pulmonary vein in patients with paroxysmal atrial fibrillation. J Cardiovasc Electrophysiol. 2001:12(12):1353with paroxysmal atrial fibrillation. J Cardiovasc Electrophysiol

13. Sato $M$, Tanaka $D$, Nakajo $M$. Meandering pulmonary veins with a common inferior trunk: An anomalous left inferior pulmonary vein entering an anomalous right inferior pulmonary vein. Radiat Med. 2007:25(8):426-429. https://doi. org/10.1007/s11604-007-0155-1

14. Lickfett L, Lewalter T, Nickenig G, Naehle P. Common trunk of the right and left inferior pulmonary veins: Previously unreported anatomic variant with implications for catheter ablation. Heart Rhythm. 2007;4(9):1244-1245. https:// doi.org/10.1016/j.hrthm.2007.02.012

15. Adey CK, SotoB, Shin MS. Congenital pulmonary vein stenosis: A radiographic study. Radiology. 1986;161(1):113-117. https://doi.org/10.1148/radiology.161.1.3763853

16. Belcourt CL, Roy DL, Nanton MA, et al. Stenosis of individual pulmonary veins Radiologic findings. Radiology. 1986;161(1):109-112. https://doi.org/10.1148/ radiology.161.1.3763852

17. Saida Y, Eguchi N, Mori K, Tanaka YO, Ishikawa S, Itai Y. Isolated pulmonary vein stenosis associated with full intrapulmonary compensation. AJR Am J Roentgenol. 1999;173(4):961-962. https://doi.org/10.2214/ajr.173.4.10511157

18. Gustafson RA, Warden HE, Murray GF, Hill RC, Rozar GE. Partial anomalous pulmonary venous connection to the right side of the heart. J Thorac Cardiovasc Surg. 1980;98:861-868.

19. Van Meter C Jr, LeBlanc JG, Culpepper WS 3rd, et al. Partial anomalous pulmonary venous return. Circulation. 1990;82(Suppl 5):195-198.

20. Posniak HV, Dudiak CM, Olson MC. Computed tomography diagnosis of partial anomalous pulmonary venous drainage to the azygos vein. Cardiovasc Intervent Radiol. 1993;16:319-320. https://doi.org/10.1007/BF02629166

21. Dillon EH, Camputaro C. Partial anomalous pulmonary venous drainage of the left upper lobe vs duplication of the superior vena cava: Distinction based on CT findings. AJR Am J Roentgenol. 1993;160:375-379. https://doi.org/10.2214/ajr.160.2.8424355

22. Almendro-Delia M, Trujillo-Berraquero F, Araji $O$, de Vinuesa PG, Fernández JM. Cor triatriatum sinistrum in an elderly man. Int J Cardiol. 2008;125(2):e27-e29.

23. Erkut B, Kocak H, Kaygin MA, Ceviz N. Cor triatriatum associated with severe valvular pulmonary stenosis and patent ductus arteriosus: An unreported constellation. Int J Cardiol. 2006;113(1):108-110. https://doi.org/10.1016/j. ijcard.2005.08.015 